\title{
Barriers and attitudes health professionals working in eating disorders experience
}

\section{Sarah Walker, Chris Lloyd}

Working with people with eating disorders is a matter of significant concern for health professionals. This study aimed to explore the attitudes of health professionals towards treating clients with eating disorders. A qualitative research design using consensual qualitative research (CQR) was used. A focus group consisting of 15 health professionals was held. The discussion was guided by a semi-structured interview schedule. Using the CQR procedure, three domains were identified: attitudes, countertransference, and barriers to providing treatment. These findings have important implications in the treatment of eating disorders.

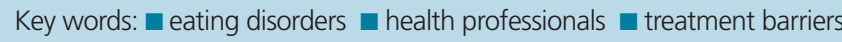

Submitted 19 December 2011, sent back for revisions 9 March 2011; accepted for publication following double-blind peer review 11 May 2011

$\mathrm{T}$ he main eating disorders are anorexia nervosa, bulimia nervosa and binge eating disorder (American Psychiatric Association, 2000).

Anorexia nervosa is a serious psychiatric illness and is characterized by a distorted body view with an obsessive fear of gaining weight, and extremely low body weight that leads to an emaciated condition (American Psychiatric Association, 2000).

Bulimia nervosa is characterized by bingeeating and inappropriate compensatory behaviours such as self-induced vomiting and/or misuse of laxatives, fasting or excessive exercise. By nature, it is often hidden and it is estimated that only one in 10 cases are detected. It it is common for people with bulimia nervosa to keep their disorder hidden for 8-10 years at great cost to their physical and psychological health (Centre of Excellence in Eating Disorders, 2010).

Binge eating disorder is characterized by recurrent binge eating without compensatory measures such as vomiting, laxative abuse or excessive exercise to counter the binge.

It is not until individuals become emaciated (as in anorexia) and/or experience severe health problems (as with anorexia and bulimia) that family and friends become aware of the disorder.

It is at this point that the individual moves from being a person who is dieting to one who is potentially dying from anorexia or bulimia. The medical complications that eating disorder clients, in particular those with anorexia nervosa, experience are fatigue, heart problems, insomnia, body temperature problems, complaints of feeling bloated, constipation and, in anorexia, growth of fine body hair (Kaplan and Garfinkel, 1999).

Treatments concern medical complications and keeping the individual alive (Franko and Erb, 1998; Kaplan and Garfinkel, 1999; Lewinsohn, Streigel-Moore and Seeley, 2000; Jacobi et al, 2004). This can be taxing on health professionals' time and energy because they often have to organize inpatient stays, be on call for emergencies and stay in constant contact with other professionals involved in treatment.

Due to the secretive nature of people with eating disorders, it is a significant challenge for health professionals to identify and diagnose disorders at an early stage and direct the course of treatment (Abell and Richards, 1996; Jacobi et al, 2004).

Health professionals treating clients with eating disorder may experience an emotional roller coaster due to managing both the complex medical risks and the psychological comorbidities often associated with eating disorder pathology such as depression and anxiety (Franko and Erb, 1998; Kaplan and Garfinkel, 1999; Strober et al, 2007).
Sarah Walker is Senior Clinical Psychologist, Eating Disorder Adult Service, Ashmore Clinic, Ashmore City, Queensland, Australia; and Chris Lloyd is Principal Research Fellow, Gold Coast Health Service District, Ashmore Clinic, Ashmore City, Queensland, and Senior Research Fellow, Behavioural Basis of Health, Griffith University, Australia

Correspondence to: Sarah Walker E-mail: Sarah_Walker@ health.qld.gov.au 
The management of eating disorders goes beyond symptom-reduction toward reinforcing opportunities to encourage clients generally to develop new ways of thinking, feeling and acting, and more adaptive interpersonal relationships.

One factor likely to interfere with adaptive functioning relates to countertransference reactions on the part of the health professional. Eating disorder clients often induce intense feelings of anger, devaluation, hopelessness, love or identification in their caregivers (Land, 2004). Countertransference is the conscious and/or unconscious reaction, behaviour or emotion that therapists have towards clients who they treat therapeutically (Land, 2004).

Most definitions acknowledge, to varying degrees, that therapists' reactions to their clients may be influenced by their own unresolved personal conflicts. When these conflicts are provoked both within and outside the therapeutic session, therapists may display avoidance behaviours, engage in reactive rather than reflective thinking, feel unsure and/or develop distorted perceptions of their clients.

These countertransference reactions may, in turn, lead to the clients forming weaker alliances with their therapists and to perceive them as less empathic (Hayes et al, 2007).

In contrast, the term transference concerns clients' emotional reactions to therapists, such as a patient's feelings for a significant person being redirected to the therapist. Transference can be manifested as an erotic attraction towards a therapist, but can be seen in many other forms such as rage, hatred, mistrust, parentification and/or extreme dependence (Hayes et al, 2007).

Both of these factors may interfere with therapy if not understood or identified and can be particularly problematic within the therapeutic without sufficient training or supervision.

Although there are a number of specialist eating disorder treatment centres, they are often unable to meet the demands on services. Hence, increasingly diverse spectrums of health practitioners working in both inpatient and community settings are becoming involved in treating such disorders. Many of these individuals have little specific training in or experience of working with this client group, yet are involved in providing treatment that is recognized as personally demanding and, at times, anxiety-provoking for the clinician (Strober et al, 2007).

The lack of training and resources required to treat the rise of people with serious and sometimes life-threatening eating disorders presenting to mental health services for assistance over the past decade may discourage some health professionals from working in this area (Vaknin, 2006).

The aim of this study was to explore the attitudes of health professionals towards treating clients with eating disorders and to develop a greater understanding of why these attitudes have developed.

\section{METHOD}

\section{Overview}

A qualitative approach was selected as the most appropriate method and consisted of one focus group.

Focus groups aim to capitalize on the interactions that occur within the group and are useful for exploring poorly understood areas and attitudes. Using a focus group enables the researcher to interact with participants to clarify responses and follow up questions (Seale and Barnard, 1998).

Data was analyzed using the consensual qualitative research (CQR) methodology (Hill et al, 1997; 2005). Broad topic areas (domains) are determined and, within each domain, core ideas are derived. Finally, themes are identified from the data in each core idea within each domain.

The primary research team used a consensus approach to reach agreement on domain, core idea and themes. One or two auditors checked each consensus judgment for accuracy and the primary research team continually referred back to the raw data to ensure accuracy of results and conclusions (Hill et al, 1997; 2005).

\section{Participants}

The participants in the study were health professionals employed within the southwest corridor from Brisbane to the Gold Coast. Participants had to hold professional qualifications in the mental health or medical professions; they had to be medical doctors, mental health nurses, occupational therapists, social workers, psychologists or psychiatrists. A sample of 15 participants, 10 female and five male, met the criteria and agreed to take part in the study. 
Table 1.

Domain 1. Attitudes of health professionals

Themes

Core idea 1.

Understanding of eating disorders

Perception of eating disorders

Core idea 2.

Preference to work with eating disorders

Providing treatment Typical
Typical

Variant

\section{Frequency Illustrative quotes}

'I know it's about control but I don't get it ... why it's so difficult to eat: I don't know why they hold onto it ... I think they're just vain to start with'

'Fear of the unknown ... I haven't got that mentality in my head, why not eat, I love food'

'You feel like your work is counterproductive ... I'm scared of saying the wrong thing ... so I avoid them ... they know more about the disorder than you do'

'I will help people who only want to be helped and this sometimes concerns me ... they don't really want to be here...'

Participants included three psychologists, two occupational therapists, two medical registrars, one consultant psychiatrist, three social workers and four mental health nurses. Nine participants had previously worked with people with eating disorders mostly in acute inpatient settings with service users of very low body weight. Two participants had worked as clinicians in an outpatient setting for people with eating disorders but did not consider themselves as specialist practitioners. Four participants had no experience of working with people with eating disorders eating disorders.

\section{Procedure}

Ethical approval was obtained from the Gold Coast Health District ethics committee and the University of Queensland ethics committee.

The team leader from the mental health clinic was given an overview of the research project and the purpose of the focus group. The team leader gained an initial expression of interest from the mental health and medical staff within the clinic during their weekly intake meeting. The team leader informed the principal researcher that a relatively high number of staff had expressed an interest; a date and time was set for the focus group and relayed to the staff.

Fifteen out of 20 health professionals who expressed an interest attended the focus group. Five staff were unable to attend because of sickness or prior commitments and sent apologies.

An information sheet was provided, outlining requirements for participation and stating that taking part was voluntary. The health professionals were given a consent form to sign. It was clearly explained to the health professionals that choosing not to participate would in no way compromise their position and confidentiality was assured.

The focus group took one hour and was conducted by a mental health clinician (a senior psychologist) in the staff meeting room at the clinic. The focus group explored barriers and the attitudes of health professionals in regard to treating service users with an eating disorder. The discussion was guided by a semi-structured format and audiotaped. The following questions were used to guide the group discussions:

What thoughts do you have when allocated a service user with an eating disorder?

What feelings do you have when working with service users with an eating disorder?

What importance do you think training has on your desire to work with eating disorders?

What are the obstacles in treating service users with an eating disorder?

\section{Data analysis}

Following the CQR methodology (Hill et al, 1997; 2005) a five-step process was used 
Table 2.

Domain 2. Countertransference

\begin{tabular}{|c|c|c|}
\hline Themes & Frequency & Illustrative quotes \\
\hline \multicolumn{3}{|l|}{$\begin{array}{l}\text { Core idea } 1 . \\
\text { Emotions }\end{array}$} \\
\hline \multirow[t]{3}{*}{ Emotions experienced } & Typical & $\begin{array}{l}\text { 'Frustrating ... it can be really frustrating to get people to } \\
\text { engage when there is clearly a problem, when they are } \\
\text { not willing ... it can be very frustrating for the clinician to } \\
\text { stay motivated' }\end{array}$ \\
\hline & & $\begin{array}{l}\text { 'You can get quite angry with them ... frustrated with } \\
\text { them when it goes on and on. I looked after a girl who } \\
\text { used to rip out the naso tube ... after some time, you } \\
\text { would get feelings of immense anger and frustration' }\end{array}$ \\
\hline & & $\begin{array}{l}\text { 'When you to see positive results, you feel excited and } \\
\text { good that things are moving forward but most of the } \\
\text { time you feel you are going round and round in circles so } \\
\text { it makes you feel a useless therapist ... it just takes too } \\
\text { long to get the rewards for your work' }\end{array}$ \\
\hline \multicolumn{3}{|l|}{$\begin{array}{l}\text { Core idea } 2 . \\
\text { Self-evaluation }\end{array}$} \\
\hline \multicolumn{3}{|c|}{ Reactions or changes in body image } \\
\hline & Typical & $\begin{array}{l}\text { 'Working with eating disorders does make you look at } \\
\text { your own body image and your of own self image ... you } \\
\text { need to be fairly intact and confident to work with them } \\
\text {... you can see them evaluating you ... it can be quite } \\
\text { distressing on a bad day...' }\end{array}$ \\
\hline & Variant & $\begin{array}{l}\text { 'İ think body image is more an issue with females due } \\
\text { to social pressures ... it doesn't bother me so much } \\
\text { being a male ... but I do think I become more aware } \\
\text { of healthy eating...' }\end{array}$ \\
\hline & Variant & $\begin{array}{l}\text { 'I feel like I'm big and huge and I'm loud or somehow } \\
\text { going to crush them with my presence ... it taps into my } \\
\text { own body image issues' }\end{array}$ \\
\hline
\end{tabular}

when analyzing the data. This included: developing domains; constructing core ideas; cross analysis; auditing; and stability check.

\section{RESULTS}

Three key domains were identified when using the CQR procedure: attitudes; countertransference; and barriers to providing treatment.

These domains, together with the core ideas, principal themes within each core idea and illustrative quotes for each theme, are set out in Tables 1-3.

\section{Domain 1. Attitudes of health professionals}

Two core ideas were identified in the domain of attitudes of health professionals. These were an understanding of eating disorders and desire to work with people with eating disorders. Examples of participants' views are given in Table 1 .

Table 1 shows that some participants struggle with understanding why someone would develop a fear of eating food.

Participants were aware that the eating disorder had to do with control. However, they felt that, underlying the disorder, service users were vain.

In terms of whether they would choose to work with people with eating disorders, participants stated they were reluctant to be allocated a client with an eating disorder as the client often knew more about the eating disorder that they did. Participants often felt that clients did not want to be treated which 
Table 3.

Domain 3. Barriers to providing treatment

\begin{tabular}{|c|c|c|}
\hline Themes & Frequency & Illustrative quotes \\
\hline \multicolumn{3}{|l|}{$\begin{array}{l}\text { Core idea } 1 . \\
\text { Case loads }\end{array}$} \\
\hline \multirow[t]{2}{*}{ Managing challenging clients } & Typical & $\begin{array}{l}\text { 'It's unrealistic to expect us to manage these clients, we don't } \\
\text { have sufficient training ... they take up so much time ... they are } \\
\text { intense ... the medical complications are scary and I don't feel } \\
\text { trained to manage them ... our case loads are too big to cope } \\
\text { with eating disorder as well' }\end{array}$ \\
\hline & Typical & $\begin{array}{l}\text { 'The obstacle is the medical risk ... it's a professional risk and we } \\
\text { have too little resources and time to manage them' }\end{array}$ \\
\hline \multicolumn{3}{|l|}{$\begin{array}{l}\text { Core idea } 2 . \\
\text { Training and supervision }\end{array}$} \\
\hline \multicolumn{3}{|l|}{ Skills/debriefing } \\
\hline & Typical & $\begin{array}{l}\text { 'We don't give the clients adequate service not because we don't } \\
\text { want to-we just don't have the training ... we simply don't know } \\
\text { what to do' }\end{array}$ \\
\hline & Typical & $\begin{array}{l}\text { 'It would help if we had adequate supervision ... you could } \\
\text { easily burn out with this population ... all the stuff we've been } \\
\text { talking about, the medical risks the countertransference, the self } \\
\text { evaluation ... if we had supervision I'd be happier taking them on' }\end{array}$ \\
\hline & Variant & $\begin{array}{l}\text { 'I had this patient in the ward. I felt frustrated. I didn't know } \\
\text { which tools to use. I was assessing him with the same tools as } \\
\text { anyone in the psych ward. I haven't been provided with enough } \\
\text { education or tools to assess him ... I don't like to accept } \\
\text { patients with an eating disorder, not because of the patient, } \\
\text { but because of me. I don't have the education' }\end{array}$ \\
\hline & Variant & $\begin{array}{l}\text { 'It makes me sad that I cannot help them ... I have a moral and } \\
\text { ethical duty to help but I don't have the skills' }\end{array}$ \\
\hline
\end{tabular}

also made them less like to choose to work with them.

\section{Domain 2. Countertransference}

Two core ideas were identified in the domain of countertransference: emotions, and self evaluation. An example of participants' views are given in Table 2.

Participants often felt frustrated when working with people with eating disorders (Table $2)$. They reported feelings of anger and frustration when treating clients that they felt contributed to the clients' resistance to treatment and slow progress when treating eating disorders.

In regard to self-evaluation, participants felt that they became more aware of their own body image issues. One participant reporting feeling 'huge and big' as service users were 'such small tiny delicate things'. Male participants were less likely to feel conscious of their own body image but one said that he had become more aware healthy eating.

\section{Domain 3. Barriers to providing treatment}

Two core ideas were identified in the domain of barriers to providing treatment: case loads and training and supervision. Examples of participants' views are given in Table 3.

Two main categories emerged. In relation to case loads, participants felt they had insufficient training or time to manage the complexities of the service users. Participants felt it was unrealistic to expect case managers who were already expected to have extensive knowledge about other mental health conditions to take on eating disorders as well.

One participant suggested that specialist case managers should be employed. Other participants felt that supervision with a specialist eating disorder clinician would increase their desire to take on people with eating disorders.

The majority of participants felt they 
lacked education on eating disorders, which reduced their willingness to take these patients on. One participant stressed it was his lack of knowledge and lack of adequate tools that prevented him from engaging in treating eating disorders, not the service users themselves.

\section{DISCUSSION}

This study sought to identify the attitudes and challenges that mental health and medical practitioners experience when treating service users with an eating disorder. The findings of the study suggest that attitudes of health professionals in terms of treating clients diagnosed with an eating disorder are related to lack of experience and negative countertransference reactions.

Health professionals may perceive themselves as trying to do a good job but, because they are not provided with adequate training, this results in feelings of inadequacy becoming more entrenched and subsequent negative attitudes that decreases their desire to work within the eating disorder population.

The focus group had three dominant key domains: attitudes; countertransference; and barriers to providing treatment.

Health professionals expressed how the formula of treatment on a superficial level appears simple in that 'all they have to do is eat'. Participants struggled to identify with service users because of the perception that food creates fear, with most participants expressing confusion that something as pleasurable as food could create such a detrimental condition.

Participants acknowledged difficulty with having empathy for service users because they knew eating disorders are ego-syntonic-they are in agreement with the service users' goals to be thin. Participants who had no experience in treating eating disorders reported a lack of empathy and a belief that the eating disorder was self-inflicted.

One participant stated she did not want to work with people with eating disorders because of the negative attitudes of senior staff who had expressed a dislike of treating eating disorders and redirected her to other areas of mental health.

Other participants said their attitudes had come from their experience of people with eating disorders as inpatients. In this situation, the service user is often in the acute phase of the illness and highly resistant to treatment. As one participant said: 'I can only have empathy for people who want help... these patients scream at us for helping them.'

The clinical implications for this finding point to education around the well-documented notion of 'starvation syndrome', which emphasizes the struggle for service users to be rational or compliant because of the effects that starvation has on the brain. It could be that attitudes may be derived from inpatient settings where service users are only admitted due to chronically low body weight so are likely to be experiencing starvation syndrome, which perpetuates their resistance to treatment.

Contributing to the attitudes of health professionals were the negative feelings of countertransference. Most participants expressed frustration followed by anger because of the highly resistant nature of the disorder. One participant summarized: 'It's not good for your confidence...it makes you feel like a useless therapist because the gains are so small...you get frustrated not because of the patient but because you can't shift them'.

Other participants said that the medical risks were so great that they felt ill equipped to manage the complex nature of eating disorders.

Interestingly, medical practitioners expressed frustration at not being able to 'fix it' because the prescription is 'food but they don't want it'. This draws attention to the dilemma that medical professionals have in treating service users with eating disorders. Being trained in medicine suggests that illness can be cured if given the correct medication. In this instance, this would be 'food'; however, food is feared and something to avoid in the pathology of the eating disorder service user. It is therefore understandable that, unless highly trained in the subtleties of the eating disorder pathology, medical professionals may be less likely to want to work with eating disorder service users and experience greater frustration.

The important implications when considering what drives attitudes of health professionals is the recognition that eating disorders are a specialist area and training needs to reflect this. As found in previous research (Reid et al, 2010) participants believed a higher level of training was necessary to deal with this service user group. 
Some participants said that they would like to treat eating disorders if further training was available.

Furthermore, the lack of training may increase countertransference, which could impede the therapeutic relationship; this has already been identified in a consumer focus group of clients with eating disorders (Walker and Lloyd, in press) as the most important factor for treatment compliance.

Another aspect of working with service users with eating disorders related to gender. Female participants expressed reactions of greater awareness of their own body image and issues. Males did not do this, except for one who said he had become "more aware of eating healthy options'.

Participants agreed that they felt they were often evaluated by service users in respect of their body shape and weight and that a therapist's body image needed to be intact to manage any countertransference issues.

Barriers to providing treatment related to the time required, the already overstretched resources of the case managers, the lack of training and inadequate supervision.

Many participants felt that they were being counterproductive in regard to treating eating disorders, with most feeling that lack of time meant they were just 'band-aiding'. This raises important considerations as to whether some kind of treatment is better than no treatment at all or, more importantly, whether this less-than-adequate service could be detrimental to the service user's health.

Another important implication is whether less-than-adequate treatment increases the countertransference experienced by practitioners and therefore reduces their wanting to treat service users.

Or is it simply that employing health professionals with no relevant training or experience is unethical? This relates to the likelihood that service users would be receiving inadequate treatment and health professionals who are expected to pick up knowledge as they went along may be at risk of experiencing burnout (Reid et al, 2010).

These findings suggest the overstretched demands of services and lack of staff retention are possibly due to staff not feeling adequately supported or trained to manage the complexities of the service users.

In many cases of complex eating disorders, especially anorexia nervosa, preventing deterioration and treating medical complications associated with low weight are very important. This, in theory, can be carried out by clinicians such as medical staff, without extensive training in eating disorders.

When it comes to helping a person to challenge or even overcome an eating disorder, and dealing with the underlying psychological issues, appropriate levels of training and supervision are necessary.

One participant expressed 'sadness' at not having the tools or resources to assist these service users. Participants agreed that specialist supervision is preferred when managing eating disorders and that treating eating disorders is a specialist area of expertise.

Many participants agreed that undergraduate studies did not provide any education on eating disorders and those with postgraduate training had received minimal education about eating disorders. Medical practitioners, in both psychiatry and medicine, reported that training was inadequate when it came to eating disorders.

\section{Limitations and further research}

One of the limitations of the focus group were that the staff who took part were all from the same local mental health clinic, which may have limited experiences of staff to draw on in regard to treating eating disorders

Many participants had previously treated eating disorders, although in a medical inpatient setting where treatment can at times be punitive, with the use of nasogastric feeding, which causes intense reactions in service users.

Most participants were case managers who were often stretched for time and, as such, may have attended the focus group with the pressure of high caseloads, which may have given caseloads undue importance.

Less experienced clinicians may have been intimidated by the experienced senior clinicians so less likely to contribute to the discussion. The findings can be considered fairly robust as 15 participants is consistent with the sample since recommended by Hill et al $(1997 ; 2005)$.

Finally, the findings are consistent with findings outlined in the literature review on attitudes of health professionals when treating service users with an eating disorder.

\section{CONCLUSION}

The dominant themes that were raised from the health professionals were: training and supervision, countertransference, and attitudes. 


\section{KEY POINTS}

- The main eating disorders are anorexia nervosa, bulimia nervosa and bingeeating disorder

- A qualitative approach was taken to investigating attitudes of health professionals towards working with clients with eating disorders. This involved one focus group consisting of 15 health professionals. Data was analysed using the consensual qualitative research method.

- Three key domains were identified. These were attitudes, countertransference and barriers to providing treatment.

- Participants believed that a higher level of training was required if these service users were to be treated more effectively.

The main findings suggest that health professionals do not have a basic knowledge of the causes, treatments and challenges associated with eating disorders that manifest into negative reactions, treatment experiences and subsequent attitudes of health professionals.

This study has highlighted health professionals' attitudes and emotional reactions. It has also highlighted training and supervision that can be targeted in a positive manner to improve the skills and wellbeing of professionals, enhance the therapeutic relationship and experience, and move towards better outcomes in this challenging clinical area. ITR

Acknowledgements: we would like especially to thank the participants who willingly gave up their time to take part in this study.

Abell SC, Richards MH (1996) The relationship between body shape satisfaction and self esteem: an investigation of gender and class differences. $J$ Youth Adolesc 28(5): 583-594

American Psychiatric Association (2000) Diagnostic and Statistical Manual of Mental Disorders. 4th edn.
American Psychiatric Association, Washington DC

Centre of Excellence in Eating Disorders (2010) Eating Disorders Resource for Health Professionals. www. ceed.org.au/professional-resources/w1/i1001228 (accessed 2 June 2011)

Franko D, Erb J (1998) Managed care or mangled care? Treating eating disorders in the current healthcare climate. Psychotherapy: Theory, Research, Practice, and Training 35(1): 43-53

Hayes JA, Yeh Y-J, Eisenberg A (2007) Good grief and not-so-good grief: countertransference in bereavement therapy. J Clin Psychol 63(4): 345-355

Hill CE, Thompson BJ, Williams EN (1997) A guide to conducting consensual qualitative research. Couns Psychol 25(4): 517-72

Hill CE, Thompson BJ, Hess, SA, Knox S, Williams EN, Ladany N (2005) Consensual qualitative research: an update. J Couns Psychol 52(2): 196-205

Jacobi C, Abascal L, Taylor CB (2004). Screening for eating disorders and high risk behavior: caution. Int $J$ Eat Disord 36(3): 280-95

Kaplan AS, Garfinkel PE (1999) Difficulties in treating patients with eating disorders: a review of patient and clinician variables. Can J Psychiatry 44(7): 665-70

Land P (2004) Thinking about feelings: working with the staff of an eating disorders unit. Psychoanal Psychother 18(4): 390-403

Lewinsohn, PM, Striegel-Moore RH, Seeley JR (2000) Epidemiology and natural course of eating disorders in young women from adolescence to young adulthood. J Am Acad Child Adolesc Psychiatry 39(10): 1284-92

Reid M, Williams S, Burr J (2010) Perspectives on eating disorders and service provision: a qualitative study of healthcare professionals. Eur Eat Disord Rev 18(5): 390-8

Seale J, Barnard S (1998) Therapy Research: Processes and Practicalities. Butterworth-Heinemann, Oxford

Strober M, Freeman R, Lampert C, Diamond J (2007) The association of anxiety disorders and obsessive compulsive personality disorder with anorexia nervosa: evidence from a family study with discussion of nosological and neurodevelopmental implications. Int $J$ Eat Disord 40 Suppl: S46-51

Vaknin S (2006) Eating Disorders and Personality. Narcissus Publications, Prague

Walker S, Lloyd C ( in press) Issues and challenges experienced by service users with eating disorders: a qualitative investigation. IJTR

\section{COMMENTARIES}

This qualitative study has successfully highlighted an important issue for community mental health services. As the authors point out, eating disorders are increasingly being treated in community mental health teams by practitioners from a range of disciplines with little or no disorder specific training in the course and outcomes of the disorders (Keel and Brown, 2010), and little or no training in treatment models

\section{This report illustrates the utility of the scientist-practi-} tioner partnership in mental health service delivery"

with the strongest evidence base (Keel and Haedt, 2008). While the general principles of recovery-oriented mental health treatment and care can often be applied generically to a range of psychiatric disorders, eating disorders are sufficiently different, chronic and challenging to require a disorder-specific approach.
The authors have shown that when mental health staff are required to treat eating disorders without sufficient training and supervision, they can lose personal and professional confidence, and may avoid treating eating disorders altogether.

The report reveals several disorder spe- 
cific challenges facing practitioners: (1) the incompleteness of our knowledge about pathogenesis, course, outcomes, and how eating disorders are maintained via a complex but unclear mix of biological, social, and psychological forces; (2) anosognosia features where clients may deny any health problem and refuse treatment; (3) the subsequent difficulties engaging clients in a therapeutic alliance, particularly when treatment is against the client's will; (4) the relative ineffectiveness of usual treatments and the long course of illness even with ongoing treatment; and (5) practitioner difficulties managing their own emotional reactions to clients. While these difficulties are not unique to eating disorders (e.g. schizophrenia, acquired brain injuries, and personality disorders are prone to anosognosia and also have treatments of mixed efficacy) the challenging combination highlights a need to provide disorder specific training.

This report illustrates the utility of the scientist-practitioner partnership in mental health service delivery. It shows how a small qualitative study in a treatment setting can initiate a programme of research, training, and enhanced clinical care which, in the long-term, promises to improve treatment outcomes. Incomplete knowledge of eating disorders and low current treatment efficacy should not deter the provision of training in the best available approaches to treatment and care.

This study suggests that staff would welcome and be reassured by further disorder specific training, even if the training focussed on the limits of our current knowledge and the mixed efficacy of treatment. The treatment issues based on practitioner experiences identified in this report would enrich such a training plan.

Qualitative studies such as this are useful for generating new research questions. In doing so, this report raises the concern that qualified mental health professionals may not be receiving sufficient disorder-specific training with respect to eating disorders in particular. If so, further research could investigate whether disorder-specific training improves clinician confidence, service user perceptions of the quality of treatment, and treatment outcomes. In the meantime, treatment and care can be further guided by input from service users regarding the staff attitudes and approaches perceived as most helpful. Although the focus of this report is appropriately on treatment services, the results from further investigations may have wider implications for other rehabilitation and community based services which may also benefit from disorder specific training in the most effective approaches to treatment and care.

Keel PK, Brown TA (2010) Update on course and outcome in eating disorders. International Journal of Eating Disorders 43(3): 195-204

Keel PK, Haedt A (2008) Evidence-based psychosocial treatments for eating problems and eating disorders. Journal of Clinical Child and Adolescent Psychology 37(1): 39-61

\section{Geoff Waghorn, PhD}

Adjunct Senior Lecturer

School of Population Health,

The University of Queensland;

Head, Social Inclusion and Translational

Research, The Queensland Centre for Mental Health Research,

Queensland, Australia

geoffwaghorn@qcmhr.uq.edu.au
$\mathrm{T}$ his article makes a welcome contribution to the sparse literature on how health professionals work with people with eating disorders. Broadly, despite emerging from a very different health care situation, their findings support our research in the North of England looking at General Practitioners' perspectives on eating disorders (Reid et al, 2010a) and at people working in specialist services' perspectives (2010b), as well as at sufferers' perspectives on how they are treated (Reid et al, 2008).

Practitioners tend to feel under-qualified to work with eating disorders and would like more training; many did not follow a clear training pathway into eating disorders specialization, but rather learned 'on the job'; some do not always have a strong grasp of the psychological processes that maintain an eating disorder; and can find people with eating disorders difficult to work with.

Walker and Lloyd interpret these concerns in terms of psychoanalytic concepts of transference. This is potentially very interesting, but perhaps over interpreting the data. The paper lacks information about the nature of the participants, the Australian health care settings where they were recruited, and what treatment models are used. In the UK, CBT is recom-

\section{${ }^{6} 6$ This article makes a welcome contribution to the sparse literature on how health professionals work with people with eating disorders"}

mended, but related therapies addressing thoughts and feelings are also in use. I look forward to further research on the psychodynamics underlying eating disorders.

If the participants in the focus group were predominantly proficient in psychological interventions for eating disorders, then transference is an appropriate interpretation. If participants were a diverse group of health care professionals who happened to work with people with eating disorders, then they may simply lack appropriate psychological understandings and consequently find client behaviours and sensitivities frustrating. The quotes used to illustrate the themes suggest lack of understanding, which confirms the need for training. 'Vanity' is, for example, an unhelpful understanding of why someone should strive to look frighteningly skeletal.

Our own research is replete with examples where a well-intended, but unskilled, remark by a health professional is problematic. For example, 'You're looking well today' can be interpreted as 'You're looking fat today.'

There are also tensions between regarding eating disorders as the remit of highly specialized services, which tend to be thin on the ground, hard to reach for many sufferers, and over-stretched, and seeing them as the responsibility of less specialized health services. An emerging model of service provision in the UK is for the local specialist team to work across an area, reaching out to patients and health professionals, rather than only treating in a clinic to which patients travel. This model enhances the skills of generalists, who are best positioned to assess and monitor people with eating disorders as they recover.

Reid M, Williams S, Hammersley R (2010a) Managing Eating Disorder Patients in Primary Care: A UK Based Qualitative Study. Eating Disorders. The Journal of Treatment and Prevention 18: 1-9

Reid M, Williams S, Burr J (2010b) Healthcare professionals' perspectives of eating disorders and service provision. European Journal of Eating Disorders. DOl:10.1002 erv.976

Reid M, Burr J, Williams S et al (2008) Eating disorders patients' views on their disorders and on an outpatients service: A qualitative study. Journal of Health Psychology 13(7): 956-60

\section{Professor Marie Reid}

Department of Psychology, University of Hull, Hull, UK M.Reid@hull.ac.uk 